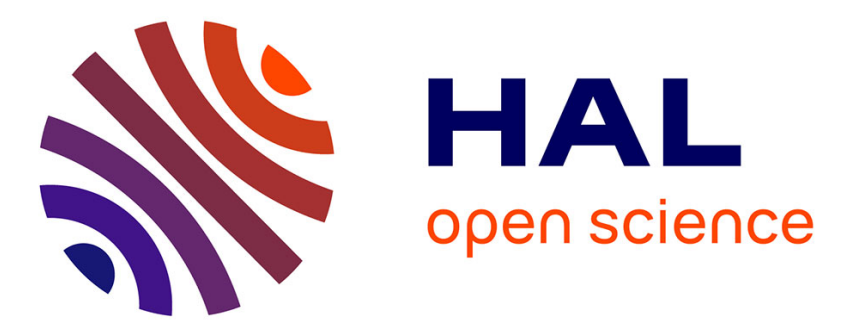

\title{
Integrated design process and sensitivity analysis of a hybrid electric propulsion system for future aircraft
}

Matthieu Pettes-Duler, Xavier Roboam, Bruno Sareni

\section{To cite this version:}

Matthieu Pettes-Duler, Xavier Roboam, Bruno Sareni. Integrated design process and sensitivity analysis of a hybrid electric propulsion system for future aircraft. electrimacs, May 2019, Salerno, Italy. hal-02489890

\author{
HAL Id: hal-02489890 \\ https://hal.science/hal-02489890
}

Submitted on 24 Feb 2020

HAL is a multi-disciplinary open access archive for the deposit and dissemination of scientific research documents, whether they are published or not. The documents may come from teaching and research institutions in France or abroad, or from public or private research centers.
L'archive ouverte pluridisciplinaire HAL, est destinée au dépôt et à la diffusion de documents scientifiques de niveau recherche, publiés ou non, émanant des établissements d'enseignement et de recherche français ou étrangers, des laboratoires publics ou privés. 


\title{
Integrated design process and sensitivity analysis of a hybrid electric propulsion system for future aircraft
}

\author{
M.Pettes-Duler $\cdot$ X.Roboam $\cdot$ B.Sareni
}

\begin{abstract}
This paper is situated in the framework of future hybrid electric aircrafts which embedded weight minimization and maximization of power efficiency are the key challenges to address fuel reduction and environmental constraints. In the first part, the integrated design process aiming the overall power train optimization is described. The second part presents models specifically oriented towards the integrated design. Finally, a sensitivity analysis is carried out at the power train system level to study the influence of both electric components specific powers and efficiencies on the Maximum Take Off Weight (MTOW) and on the fuel burn of the hybrid propulsion aircraft.
\end{abstract}

\section{Introduction}

Nowadays, transport is the worldwide fastest growing sector [1] which significantly contributes to environmental degradation. Finding sustainable solutions is a key challenge to solve this issue especially for the aircraft sector which represents about $2 \%$ of the global $\mathrm{CO}_{2}$ emissions. The Clean Sky (H2020 EU) project assists with the aircraft manufacturers finding aircraft cleaning/noiseless solutions. Currently hybrid-electric or all electric aircrafts are not commercialized but several aircraft manufacturers explore the future of electric flight. Airbus has teamed up with Rolls Royce and Siemens to build a 100-passenger hybrid-electric technology flight demonstrator, E-Fan X, scheduled for 2020 [2]. The same year, backed by Boeing and Jetblue technology ventures, Zunum Aero, a hybrid electric aircraft manufacturer startup, plans to fly a 12-passenger hybrid electric prototype in 2020 [3]. The hybrid electric technology is taking off and the studies too.

It exists several electrified propulsion architectures: Full electric, Turboelectric and Hybrid Electric. A complete state of the art has been made by the National Aeronautics and Space Administration (NASA) [4] where several electrified propulsion architectures (series hybrid/ parallel hybrid/ series-parallel partial hybrid /turbo-electric) have been studied with the pursued targets to think the aircraft of tomorrow. Many assessments have been done to estimate fuel saving quantity. In the same idea, the University of Michigan proposes different architectures [5] in this paper, a deep study is made on future electric components. The following step in the Technology Readiness Level (TRL) is the validation of concept through models. The NASA develops a mission analysis coupled with a regional aircraft sizing [6], by means of very simple models to estimate the weight of a parallel hybrid-electric aircraft. In the same idea, a complete study has been done in Airbus with ICA and LAPLACE labs [7] about hybrid electric propulsive architectures for a regional aircraft. In those works, the overall aircraft architecture has been studied taking into account both energy and aerodynamics benefits. Hybridization with electric auxiliary sources (batteries or fuel cells) may also offer the opportunity to redesign the Internal Combustion Engines by limiting mechanical power demand constraints in particular flight sequences thus allowing to optimize the engine weight [8] and fuel consumption. The obtained results are the same for all of these hybrid architectures: hybrid electric powertrains are heavier than conventional thermal systems. But the global gain, due to aerodynamics, engine redesign and energy optimization are often positive in terms of fuel burn. These studies clearly emphasize the technological sensitivity: the lower the MTOW, the lower the fuel burn. The key challenge is then to minimize embedded weights by optimizing efficiencies and specific powers.

This objective is the main target of the HASTECS (Hybrid Aircraft Academic reSearch on Thermal and Electrical Components and Systems) EU project that aims at coupling thermal and electrical studies for a regional aircraft. Only a series hybrid electric architecture has been studied in this project as it leads to huge power constraints on the electric power train, the thrust being fully provided by electric devices. From an input data set and given environment 
conditions (temperature, pressure, aircraft speed, etc) we use different "surrogate" models to simplify assessments of efficiencies and masses from each device to the whole powertrain. Unlike the previous references, a fixed aircraft structure is considered. Only the propulsive system is refined through a looped process linking weight variations and thrust consequences as described in section 2: this integrated design approach allows assessing energy efficiency and mass benefits. As in some examples described in section 3, the main issue of this study is to provide surrogate models in view of an integrated design allowing to efficiently progress (with moderate computation cost) towards the optimal trade-off of the whole hybrid electric powertrain. Finally, after setting up the integrated design process, a sensitivity analysis is carried out in the last section showing the effects of variations on both specific power and efficiency of the main electric devices at the system level.

\section{Integrated design process}

A series hybrid electric propulsion system (see Fig.1) is composed of gas turbines as main power sources that drive electric generators with rectifiers supplying a $\mathrm{uHVDC}^{1}$ Electric Power Distribution Unit (EPDU). This latter is also powered by auxiliary sources composed of batteries or fuel cells. This uHVDC power distribution unit supplies inverter fed electric motors (here 4 motors) which drive propellers through gearbox. For each component of the hybrid electric propulsive device, a "system-oriented design model", also called "surrogate model", must be integrated into a global looped process estimating the MTOW at aircraft level and the fuel consumption from Turboshaft power demand. In this framework, "surrogate models" based on simplified analytic derivation, scaling, regression laws or response surfaces are necessary to address the integrated design process objectives with moderate computation cost.

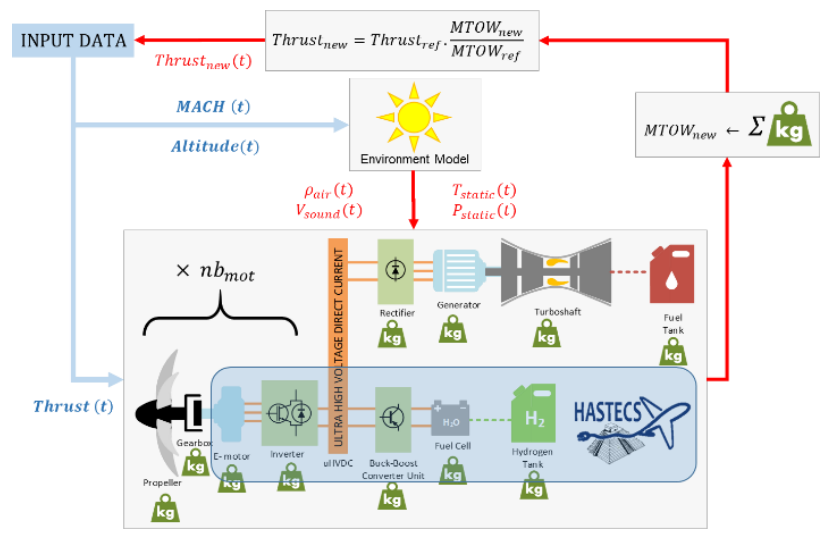

FIG.1 : INTEGRATED DESIGN PROCESS

\footnotetext{
${ }^{1}$ uHVDC means "ultra-high voltage" DC" standards beyond HVDC bus (+/-270V), leading to bus voltages in the range of $k V s$.
}

Both efficiency and mass are assessed from each component model at the end of each iteration of the looped process; masses are added in the whole powertrain to be included in the MTOW. After an iteration, based on the new (after redesign) MTOW (MTOW ${ }_{\text {new }}$ ) and its ratio versus the weight reference value $\left(\mathrm{MTOW}_{\text {ref }}\right)$ at the initial point of the process, a new thrust must be derived:

$$
\text { Thrust }_{\text {new }}=\text { Thrust }_{\text {ref }} \times \frac{M T O W_{\text {new }}}{M T O W_{\text {ref }}}
$$

Thus, by considering the evolution of "new" variables displayed in (1) at each iteration, an implicit looped process is achieved which is stopped when the MTOW error between two successive iterations is lower than $50 \mathrm{~kg}$. The process is initialized with a full thermal reference aircraft with a $M T O W_{\text {ref }}$ of $20 \mathrm{~T}$. Then, adding the embedded weights corresponding with the electric devices (power electronics, electric motors, auxiliary source, cables), new MTOW and consequently new thrust values are derivated. Our looped simplified model has been validated with reference to a complete aerodynamic model described in [7]. For a final MTOW of $26 \mathrm{~T}$, the results obtained by both models are quite similar (see Fig 2): the accordance of both thrust shapes over the flight mission allows validating simplification assumptions with the looped process. Note that this implicit loop converges within 10 iterations which corresponds to an acceptable CPU cost in view of an integrated design by optimization.

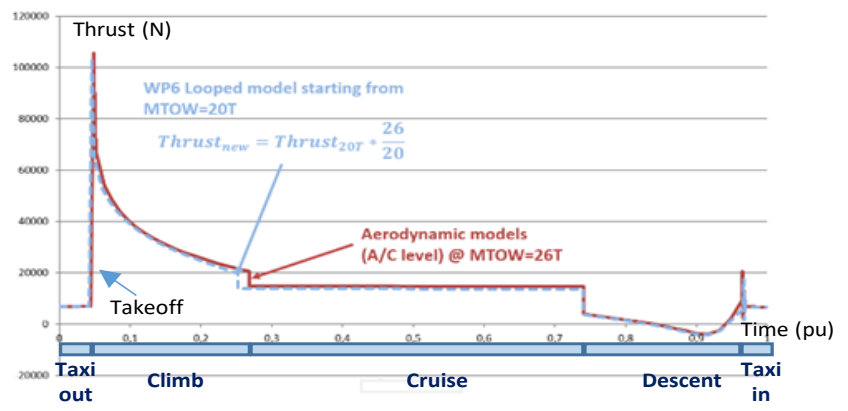

FIG.2 : COMPARISON OF AERODYNAMIC AND LOOPED MODELS

\section{Integrated design oriented models: some examples.}

From AIRBUS side, input data have been given:

- Environmental aircraft data: Altitude $(t)$

- Mach speed along the mission profile: $M A C H(t)$

Given these inputs, some examples of surrogate models are proposed to design the hybrid-electric power train of the studied aircraft. Readers will find more detailed models in [7]. 


\subsection{Environment model}

An environment model is required to design different components of the power train (turboshaft, propeller) over the flight mission. Main environment variables are derived:

$$
\begin{aligned}
& P_{\text {static }}=101325 \times\left(1-\frac{\text { Altitude }}{44331}\right)^{5.256} \\
& T_{\text {static }}=288.15-0.0065 \times \text { Altitude }+ \text { DISA } \\
& \rho_{\text {air }}=0.0034837 \times \frac{P_{\text {static }}}{T_{\text {static }}} \\
& P_{\text {dynamic }}=P_{\text {static }} \times\left(1+0.2 \times M A C H^{2}\right)^{3.5} \\
& T_{\text {dynamic }}=T_{\text {static }} \times\left(1+0.2 \times M A C H^{2}\right) \\
& V_{\text {sound }}=\sqrt{401.8 \times T_{\text {static }}}
\end{aligned}
$$

Where Altitude based on the input flight mission is in meter, DISA is the temperature difference from the International Standard Atmosphere (ISA). $\rho_{\text {air }}$ is the air density in $\mathrm{kg} / \mathrm{m}^{3}$. Finally, static and dynamic pressures $\left(P_{\text {static }}, P_{\text {dynamic }}\right)$ and temperatures $\left(T_{\text {static }}, T_{\text {dynamic }}\right)$ are respectively assessed in $[\mathrm{Pa}]$ and in $[\mathrm{K}]$. These variables will be used in particular in turboshaft and propeller models.

\subsection{Propeller model}

A 6-bladed variable-pitch propeller is considered. The propeller geometry is sized by two equations. The same tip speed limit and the same maximum shaft power are considered as for the ATR 72 propeller used in [7]. The propeller diameter can be sized from the maximum shaft power $\left(P_{\text {max }}\right.$ shaft $)$ giving the maximum rotation speed $\left(N_{\text {prop }}\right)$, and the propeller mass $\left(M_{\text {prop }}\right)$ :

$$
\begin{aligned}
& D_{\text {prop }}=3.93 \times \sqrt{\frac{P_{\text {max }} \text { shaft }}{2.4 \times 10^{6}}} \\
& N_{\text {prop }}=1200 \times \frac{3.93}{D_{\text {prop }}} \\
& M_{\text {prop }}=185 \times\left(\frac{D_{\text {prop }}}{3.93}\right)^{2}
\end{aligned}
$$

Where $D_{\text {prop }}$ is the corresponding diameter. The model is based on the Disk Actuator Theory (16) with a saturation function at low speed which is implemented in (15). In (13), the maximum thrust $T_{\max }$ has been estimated. The use of the actuator disk theory during low speed phases tends to over predict the propeller thrust, that is why we have refined the thrust $T_{v i r}$ in a saturation function (15) from the real thrust $T_{\text {real }} . T_{\text {real }}$ comes from the input data.

$$
\begin{aligned}
& k P=\frac{1}{\rho_{\text {air }}} \quad 0.1 \leq k P \leq 1.5 \\
& k=1.6+\frac{\frac{V_{A / C}}{3.93 \times 1200}}{60} \\
& T_{\text {max }}=10^{f(k P)} \cdot P_{\text {max }_{\text {shaft }}}
\end{aligned}
$$

$$
\begin{aligned}
& f(k P)=\alpha_{\text {prop }}+\beta_{\text {prop }} \times \log (k P)^{\gamma} \\
& T_{\text {vir }}=\left(\frac{2 . k \cdot T_{\text {max }}}{\pi}\right) \times \tan \left(\frac{T_{\text {real }} \pi}{2 . k . T_{\text {max }}}\right) \\
& P_{\text {shaft }}=\frac{1}{2 k_{\text {eff }}}\left(V_{A / C} T_{\text {vir }}+\right. \\
& \left.\sqrt{\left(V_{A / C} \cdot T_{\text {vir }}\right)^{2}+\frac{2 T_{\text {vir }}^{3}}{\rho_{\text {air }} A_{\text {prop }}}}\right)
\end{aligned}
$$

Where $k P$ is the input value of the linear regression of the model (14). $\rho_{\text {air }}$ is the air density varying during the flight mission in $\mathrm{kg} / \mathrm{m}^{3} . V_{A / C}$ is the aircraft speed in $\mathrm{m} / \mathrm{s}$ also defined by the mission profile. We have defined an advance ratio $k$ for the saturation function. $f(k P)$ is the linear regression function used by the model where $\alpha_{\text {prop }}, \beta_{\text {prop }}$ and $\gamma$ are constant values. After that, we can use the disk actuator theory formula with a constant value $k_{\text {eff }}=0.9$ and with the propeller disk area: $A_{\text {prop }}=\frac{\pi \cdot D_{\text {prop }}^{2}}{4}$.

\subsection{Gearbox model}

For the gearbox, the linear regression model proposed by NASA in [6] is considered for estimating the mass:

$$
\begin{aligned}
& \text { Gbox }=\left(\frac{P_{\text {propHP }}}{R P M_{\text {prop }}}\right)^{0.75} \times R_{\text {gbox }}^{0.15} \\
& M_{\text {Gbox }_{L B S}}=-37.43+116.33 \times \text { Gbox } \\
& \eta_{\text {Gbox }}=0.985
\end{aligned}
$$

Where $P_{\text {propHP }}$ is the maximum propeller shaft power in horsepower [HP], RPM $M_{\text {out }}$ the propeller rotation speed in [rpm] and $R_{\text {gbox }}$ is the gearbox ratio. A linear function allows estimating the gearbox weight in [lbs] (18). A constant efficiency value is finally assessed in (19).

\subsection{Turboshaft model}

The Turboshaft model is based on response surfaces. We consider three inputs: the static power at sea level $P_{S L S}$, the ratio between total and static pressures at sea level $\delta[\mathrm{Pa}]$ and the ratio between total and static temperatures at sea level $\theta[\mathrm{K}]$ previously calculated in (5) and (6). From these inputs, a one column-vector is derived in (22) to assess the maximum mechanical turboshaft power $P_{\text {max }_{\text {shaft }} \text { GT }} \cdot \alpha_{1}$ and $\beta_{1}$ are two constant values of the linear regression. A convenient $P_{S L S}$ value must be designed in order to supply conveniently the hybrid electric propulsion during the whole flight mission.

$$
\begin{aligned}
\delta & =\frac{P_{\text {dynamic }}}{101325} \\
\theta & =\frac{T_{\text {dynamic }}}{288.15}
\end{aligned}
$$




$$
x_{C}=\left[\begin{array}{c}
\log \left(P_{S L S_{k W}}\right) \\
\log (\delta) \\
\log (\theta) \\
\log \left(P_{S L S_{k W}}\right)^{2} \\
\log (\delta)^{2} \\
\log (\theta)^{2} \\
\log \left(P_{S L S_{k W}}\right) \times \log (\delta) \\
\log \left(P_{S L S_{k W}}\right) \times \log (\theta) \\
\log (\delta) \times \log (\theta)
\end{array}\right]
$$

With the same vector $\left(x_{c}\right)$, the maximum Power Specific Fuel Consumption $P S F C_{\max }$ is assessed (in $[\mathrm{kg} / \mathrm{s} / \mathrm{kW}$ ] in (24): it corresponds to the turboshaft PSFC when this engine provide its maximum power leading to a minimum consumption. For the real turboshaft fuel consumption, we have considered a ratio ( Part $_{\text {load }}$ ) between the maximum mechanical power and the required power function of the environmental data $\delta$ and $\theta$ in (25). Another linear regression is used to estimate the actual PSFC (27) from which the fuel flow rate is defined given a required power $P_{\text {required }}$.

$$
\begin{aligned}
& P_{\text {PSF }}=10^{\alpha_{2}+\beta_{2} \cdot x_{C}} \\
& \text { Part }_{\text {load }}=\frac{P_{\text {required }}}{P_{\text {max }_{\text {shaft }}} \times \delta \times \sqrt{\theta}} \\
& y=\left[\begin{array}{c}
\log \left(\text { Part }_{\text {load }}\right) \\
\log \left(\text { Part }_{\text {load }}\right)^{2} \\
\ldots \\
\log \left(\text { Part }_{\text {load }}\right)^{10}
\end{array}\right] \\
& P S F C=10^{\alpha_{3}+\beta_{3} \cdot y} \times \frac{P S F C_{\text {max }}}{\theta} \\
& D_{m_{\text {fuel }}}=P S F C \times \frac{P_{\text {required }}}{1000}
\end{aligned}
$$

In this model, the specific fuel consumption variation is taken into account: As displayed on Fig 3, the turboshaft consumption is minimum at $100 \%$ of the rating power [7]. Contrarily, at low rating, the SFC evolution may be referred to a hyperbolic function (see Fig.3). In that way, using secondary energy source in taxi and descent phases switching off the main thermal source could be interesting in a hybrid electric aircraft. An efficient, reliable and fast starting system is mandatory.

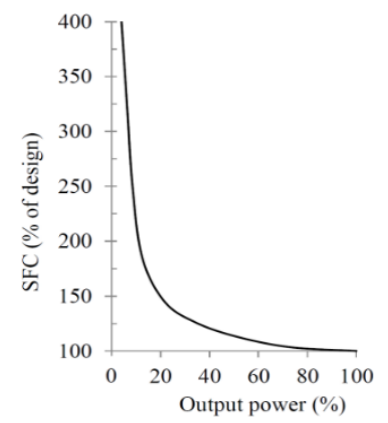

FIG.3: SPECIFIC FUEL CONSUMPTION EVOLUTION VERSUS RATING POWER.
The turboshaft mass is difficult to estimate. For that purpose, a typical specific power of $9.86 \mathrm{~kW} / \mathrm{kg}$ is assessed from experimental data set [7]. Finally, the fuel mass is obtained by the time integral of the mass flow rate (29):

$$
\begin{aligned}
& M_{\text {fuel }}=\int D_{m_{\text {fuel }}}(t) d t \\
& M_{\text {turboshaft }}=P_{S L S} \times P_{S P E}
\end{aligned}
$$

\subsection{Electric component models}

For the electric components, technological models with corresponding design are currently achieved in the HASTECS project. However, in this paper mainly oriented towards system level sensitivity analysis, very simple models based on assessments with fixed efficiency and specific power/energy targets have been considered. In the HASTECS project, two targets have been challenged for 2025 and for 2035 as displayed in Table 1. In this latter table of assessments, future 20xx target has been added with more

\begin{tabular}{|c|c|c|c|}
\hline & $\begin{array}{l}2025 \\
\text { target }\end{array}$ & $\begin{array}{l}2035 \\
\text { target }\end{array}$ & $\begin{array}{l}20 x x \\
\text { target }\end{array}$ \\
\hline \multicolumn{4}{|c|}{ Emotor/ Egenerator } \\
\hline$S P+$ cooling & $5 \mathrm{~kW} / \mathrm{kg}$ & $10 \mathrm{~kW} / \mathrm{kg}$ & $15 \mathrm{~kW} / \mathrm{kg}$ \\
\hline Efficiency & $96 \%$ & $98.5 \%$ & $99 \%$ \\
\hline \multicolumn{4}{|c|}{ Power Electronics } \\
\hline$S P+$ cooling & $15 \mathrm{~kW} / \mathrm{kg}$ & $25 \mathrm{~kW} / \mathrm{kg}$ & $35 \mathrm{~kW} / \mathrm{kg}$ \\
\hline Efficiency & $98 \%$ & $99.5 \%$ & $99.8 \%$ \\
\hline \multicolumn{4}{|c|}{ Fuel Cell - Liquid H2 } \\
\hline$H_{2}+\operatorname{tank} S E$ & & $3.3 \mathrm{kWh} / \mathrm{kg}$ & \\
\hline Auxiliary $S P$ & & $1.3 \mathrm{~kW} / \mathrm{kg}$ & \\
\hline Stack $S P$ & & $4 \mathrm{~kW} / \mathrm{kg}$ & \\
\hline \multicolumn{4}{|l|}{ DC Bus } \\
\hline Ultra $H V D C$ & & $2000 \mathrm{~V}$ & \\
\hline
\end{tabular}
aggressive assumptions. In our case, specific powers of the electric motors, (respectively electric generators) and power electronics (rectifiers and inverters) include the cooling system. A liquid hydrogen storage with fuel cell stack are considered in this study with corresponding assesments in Table 1[12].

$S P=$ Specific Power $-S E=$ Specific Energy

Table 1 : Electric component assessments

Aggressive targets have been chosen, but certain targets are already achieved. In particular Siemens[9], with the electric motor SP260D at $5.2 \mathrm{~kW} / \mathrm{kg}$. The University of Illinois is 
designing and building a permanent magnet synchronous motor to exceed a specific power of $13 \mathrm{~kW} / \mathrm{kg}$ and efficiency of 96 percent showing that these targets can be reached [10]. Concerning the inverters, General Electric [11] has reached a specific power by $19 \mathrm{~kW} / \mathrm{kg}$ for its product.

Other simple models have been developed to assess cable weights and losses, following the transferred power, the voltage level and the cable type (AC or DC).

Based on this model set, the mass distribution of the hybrid power train is displayed in Fig. 4 with the particular assessments dealing with the "2035 Target".

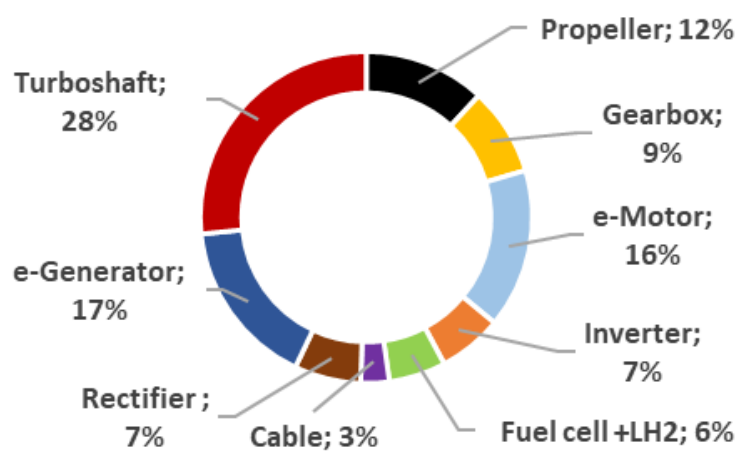

FIG.4: HYBRID POWER TRAIN MASS SHARING.

\section{Sensitivity analysis at system level}

We consider a hybrid-electric aircraft composed of two same sized turboshafts which turn generators to supply the electric powertrain. The power distribution over the flight sequences is displayed on Fig. 5: in this management strategy, fuel cells are used during full electric taxi and descent phases which may correspond to a "light hybridization scenario". For the other phases, the power is here equally shared between turboshafts. The sensitivity analysis consists in varying both the efficiencies and specific powers of two device classes (power electronics and electric machines) of the hybrid electric conversion chain with regard to the 2025 and 2035 targets.

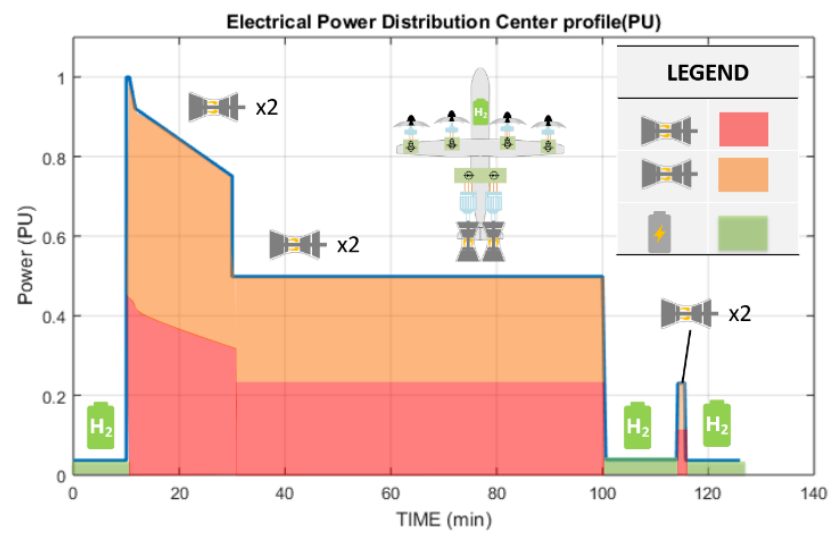

Fig.5: POWER DISTRIBUTION BETWEEN SOURCES.
In the first analysis (see Fig. 6/Fig.7/Fig.8/Fig.9), the influence of specific power and efficiency variations are separately estimated for each class of device.

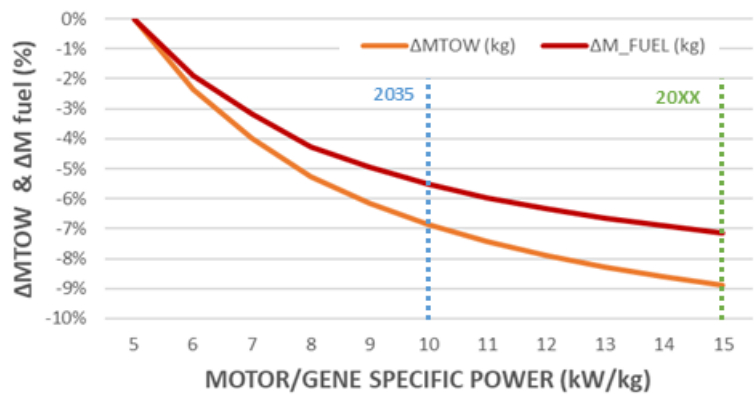

Fig. 6: IMPACT OF SPECIfic PoWer variations OF ELECTRIC MOTOR/GENERATOR ON THE MTOW AND THE FUEL MASS FROM THE 2025 TARGET.

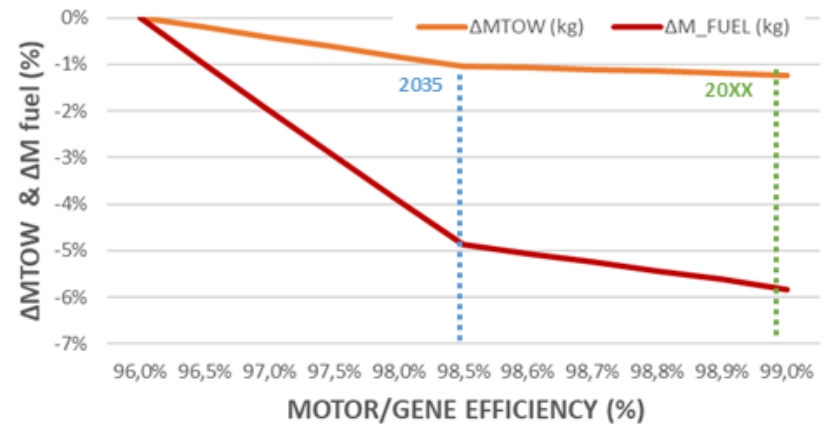

FIG.7 IMPACT OF EFFICIENCY VARIATIONS OF ELECTRIC MOTOR/GENERATOR ON THE MTOW AND THE FUEL MASS FROM THE 2025 TARGET.

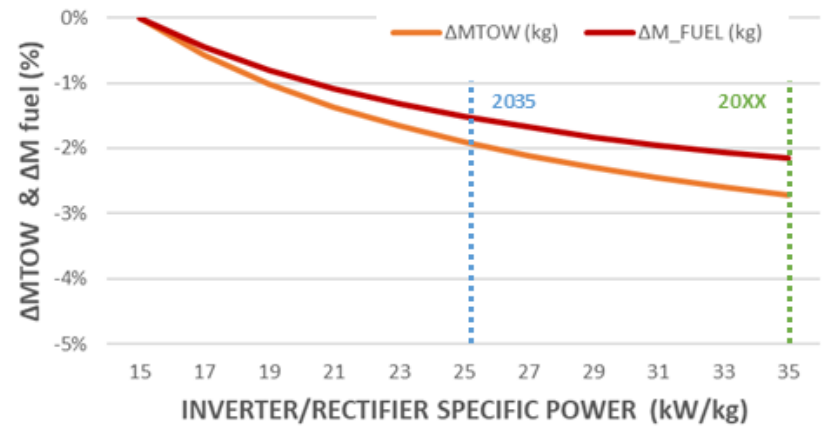

Fig.8: IMPACT OF SPECIFIC POWER VARIATIONS OF INVERTERS/RECTIFIERS ON THE MTOW AND THE FUEL MASS FROM THE 2025 TARGET. 


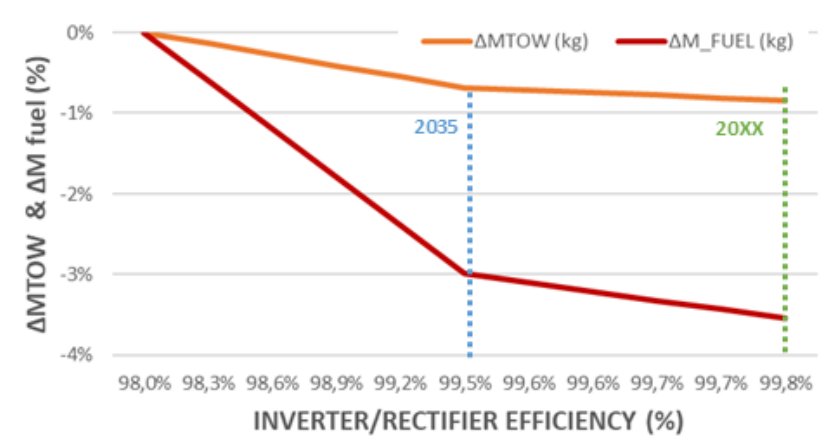

FIG.9: IMPACT OF EFFICIENCY VARIATIONS OF INVERTERS/RECTIFIERS ON THE MTOW AND THE FUEL MASS FROM THE 2025 TARGET.

It can be noticed that the impact of technological progress both in terms of specific powers and efficiency is significant on the fuel burn even if this impact is slightly lower for power electronics than for electromechanical converters. It can also be seen that both progress axis (efficiency and specific power) are really influent.

The following analysis deals with the sensitivity of same factors on the whole hybrid electric system by coupling all the elements of the system in the same figures.

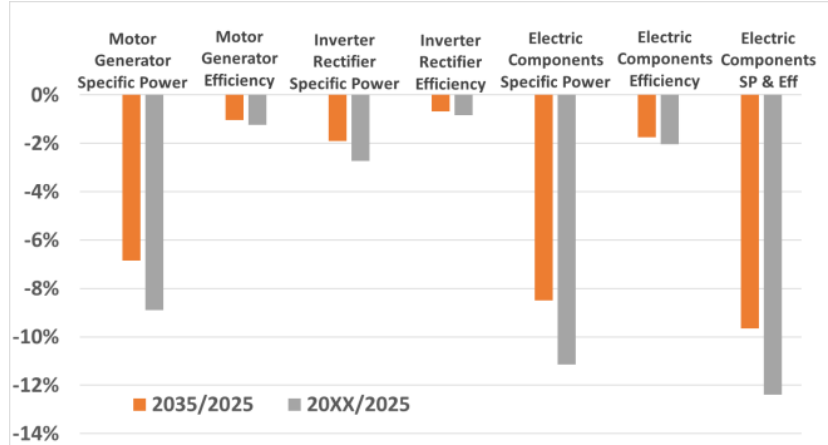

FIG.10: MTOW VARIATIONS VERSUS TECHNOLOGICAL IMPROVEMENT OF THE ELECTRIC CONVERSION CHAIN FROM THE 2025 TARGET

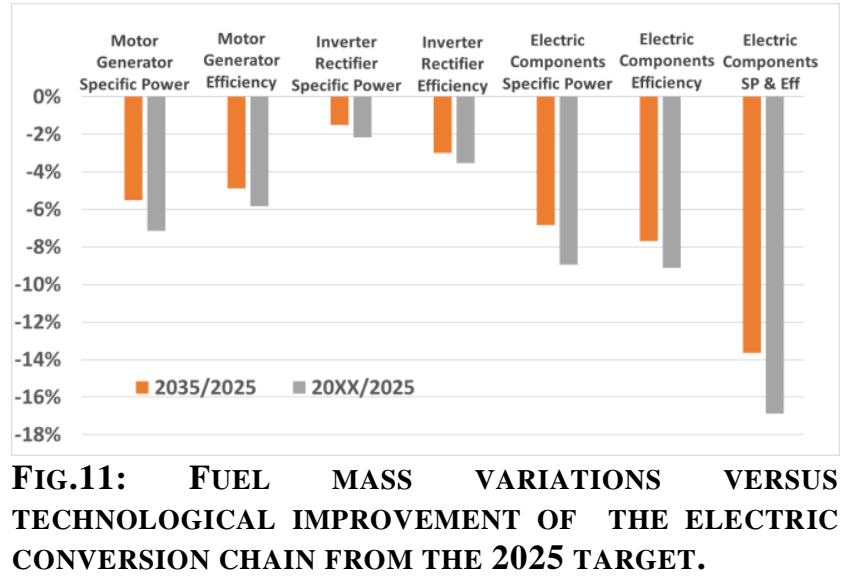

In the final figures, the two influence factors have been coupled (see Fig.10 and Fig.11). In this last sensitivity analysis, it is interesting to gather the two influent factors (specific powers and efficiencies) which characterize the technological and conceptual advance in terms of power integration and efficiency. With reference to the less aggressive assumptions (target 2025) and regarding the targets 2035 then 20XX assessments, the whole weight would be reduced by more than $12 \%$ (see Fig.10) when the fuel burn is reduced by $17 \%$ (see Fig.10). To conclude, electric components specific power is more sensitive to lower the MTOW. But the efficiency effect is not negligible: a trade-off between both specific powers and efficiencies has to be find.

\section{Conclusions}

A series hybrid-electric aircraft architecture performance is "strongly" linked with specific power and efficiency of each electric component. The whole embedded weight (MTOW) of a hybrid structure is a priori higher than for a full thermal chain. Two different progress axis exist to minimize the embedded weight: the specific power of each device as well as its efficiency. When adding supplementary masses of electric devices, there is a snowball effect with the MTOW which leads to enhance the aircraft thrust and consequently to enhance fuel consumption. Fortunately, energy gains offered by a higher efficiency of the electric chain, especially at low power operation (taxi and descent phases), compensate the weight increase. But this paper emphasizes why both specific powers and device efficiency have a huge impact on the MTOW and consequently the fuel burn.

Future works in the HASTECS project consist in a more precise sensitivity analysis based on the technical models of power electronics and electromechanical converters. The aim of this prospect is to find the more sensitive input parameters which may be the decision variable of our future system design optimization. For that purpose, sizing models of electric machines and power electronics have to be refined but sufficiently simplified to be included in an integrated design process involving the whole power train.

\section{Acknowledgements}

This project has received funding from the [European Union Horizon 2020 (cleansky 2 JTI) research and innovation programme, 2014-2024] under grant agreement No 715483.

\section{References}

[1].X. Roboam,and B.Sareni, and André DeAndrade, More Electricity in the Air: Toward Optimized Electrical Networks Embedded in More-Electrical Aircraft. (2012) IEEE Industrial Electronics Magazine, vol. $6\left(n^{\circ} 4\right)$. pp. 6-17. ISSN $1932-4529$ 
[2]. Rolls Royce (2018). The E-FAN X programme https://www.rolls-royce.com/media/ourstories/insights/2018/paul-stein-talks-about-e-fan-x.aspx

[3].Zunum Aero (2018).

https://www.jetblueventures.com/portfolio/zunum-aero/

[4]. Ralph H. Jansen, Dr. Cheryl Bowman, Amy Jankovsky, Dr. Rodger Dyson, and James Felder, "Overview of NASA Electrified Aircraft Propulsion Research for Large Subsonic Transports“, AIAA Propulsion and Energy 2017 Forum; 10-12 Jul. 2017; Atlanta, GA; United States.

[5]. B. J. Brelje and J. R. R. A. Martins, "Electric, Hybrid, and Turboelectric Fixed-Wing Aircraft: A Review of Concepts, Models, and Design Approaches",Progress in Aerospace Sciences, 2018

[6]. K. R. Antcliff, M. D. Guynn, T. Marien, D. P. Wells, S. J. Schneider,and M. J. Tong, "Mission Analysis and Aircraft Sizing of a Hybrid-Electric Regional Aircraft," in 54th AIAA Aerospace Sciences Meeting, American Institute of Aeronautics and Astronautics, San Diego,Californie, USA, January 2016.

[7]. J. Thauvin, "Exploring the design space for a hybrid-electric regional aircraft with multidisciplinary design optimisation methods", PhD Université de Toulouse, France, October 2018.

[8]. Sgueglia, Alessandro and Schmollgruber, Peter and Bartoli, Nathalie and Atinault, Olivier and Bénard, Emmanuel and Morlier, Joseph "Exploration and Sizing of a Large Passenger Aircraft with Distributed Electric Ducted Fans". (2018) In: AIAA - Scitech 2018, 8 January 2018 - 12 January 2018 (Kissimmee, United States).

[9]. Siemens (2015). Electric propulsion components with high power densities for aviation.

https://nari.arc.nasa.gov/sites/default/files/attachments/Korbin ian-TVFW-Aug2015.pdf

[10]. X. Yi, A. Yoon, K. Haran, " Multi-Physics Optimization for High-Frequency Air-Core Permanent-Magnet Motor of Aircraft application ", 2017 IEEE International Electric Machines and Drives Conference (IEMDC), Miami, FL, USA pp. 1-8

[11]. D. Zhang, "NASA SiC Light-Weight Inverter for MWPower (SLIM) - Phase I," 55th AIAA Aerospace Sciences Meeting, AIAA, Reston, VA, 2017.

[12]. F. Michel, H. Fieseler, L.allidieres "Liquid Hydrogen Technologies for Mobil Use", WHEC, 16 June 2006, Lyon, France. 